\title{
GLOBAL ATTRACTIVITY RESULTS FOR COMPARABLE SOLUTIONS OF NONLINEAR HYBRID FRACTIONAL INTEGRAL EQUATIONS
}

\author{
BAPURAO C. DHAGE
}

Abstract. We present a couple of global attractivity and asymptotic stability results for the comparable solutions of a certain hybrid functional nonlinear fractional integral equation with a linear perturbation of first kind on the unbounded intervals of real line under some weaker partially Lipschitz and partially compactness type conditions. We employ a new partially measure theoretic fixed point theorem in our analysis and develop an algorithm for the solutions. We claim that the results are new to the literature.

Mathematics subject classification (2010): 45G10, 45J05.

Keywords and phrases: partially ordered space, measure of noncompactness, hybrid fixed point theorem, fractional integral equation, existence, attractivity and stability.

\section{REFERENCES}

[1] J. APPELL, Measures of noncompactness, condensing operators and fixed points : An applicationoriented survey, Fixed Point Theory 6 (2005), 157-229.

[2] J. Banas, K. Goebel, Measures of Noncompactness in Banach Space, in: Lecture Notes in Pure and Applied Mathematics, Vol. 60, Dekker, New York, 1980.

[3] J. BAnAS, B. C. Dhage, Global asymptotic stability of solutions of a functional integral equations, Nonlinear Analysis, 69 (2008), 1945-1952.

[4] S. CARL, S. HeKkIL Ä, Fixed Point Theory in Ordered Sets and Applications, Springer, 2011.

[5] B. C. DHAGE, Fixed point theorems in ordered Banach algebras and applications, Panamer. Math. J., 9, (4) (1999), 93-102.

[6] B. C. DHAGE, Hybrid fixed point theory in partially ordered normed linear spaces and applications to fractional integral equations, Differ. Equ Appl., 5 (2013), 155-184.

[7] B. C. DHAGE, Nonlinear $\mathscr{D}$-set-contraction mappings in partially ordered normed linear spaces and applications to functional hybrid integral equations, Opuscula Math., (to appear).

[8] B. C. DhaGe, Partially condensing mappings in ordered normed linear spaces and applications to functional integral equations, Tamkang J. Math., 45 (2014).

[9] S. Heik Kilä And V. Lakshmikantham, Monotone Iterative Techniques for Discontinuous Nonlinear Differential Equations, Marcel Dekker inc., New York 1994.

[10] M. A. KRasnosels KiI, Topological Methods in the Theory of Nonlinear Integral Equations, Pergamon Press 1964.

[11] V. Lakshmikantham, S. Leela and J. Vasundhara DeVi, Theory of fractional dynamic systems, Cambridge Scientific Publishers, 2009.

[12] J. J. NiETO AND R. RODRIGUEZ-LoPEZ, Contractive mappings theorems in partially ordered sets and applications to ordinary differential equations, Order 22 (2005), 223-239.

[13] I. Podlubny, Fractional Differential Equations, Academic Press New York 1999. 